\title{
Indeterminacy and Investment Adjustment Costs
}

\author{
Jinill $\mathrm{Kim}^{\mathrm{x}}$
}

First draft: February 1997

This draft: J une 19, 1999

\begin{abstract}
A bstract
It has been widely known that neoclassical growth models with sud cient increasing returns in production may feature indeterminacy. This note shows that investment adjustment costs increase the required degree of increasing returns for indeterminacy to arise. Under empirically plausible levels of investment adjustment costs, we need implausibly large degree of increasing returns to generate indeterminacy.
\end{abstract}

Key words: Indeterminacy, I nvestment Adjustment Costs.

J EL classi..cation: E22, E 32.

\section{Introduction}

Neoclassical growth models with suф cient increasing returns to scale may feature indeterminate dynamics, in the sense that there is a continuum of equilibrium paths which converge to the unique steady state. The presence of indeterminacy is an interesting phenomenon since models with indeterminacy can generate self-ful..lling business cycle łuctuations. The presence and the role of indeterminacy have been studied by B enhabib and Farmer (1994) and the references in Benhabib and Farmer (1997). ${ }^{1}$

${ }^{2} 114$ Rouss Hall, Department of Economics, University of Virginia, Charlottesville, VA 22903. Telephone: (804)924-7581. E-mail: j k9n@i rgi ni a. edu. Comments from B ob K ing, K evin Lansing, and seminar participants at 1998 SCE conference and various universities are greatly appreciated. All the remaining errors are, of course, mine.

${ }^{1}$ Benhabib and Farmer (1997) review this literature from the perspective of macroeconomics. 
The concept of adjustment costs has been widely used in the literature on investment, e.g. A bel and Blanchard (1983). ${ }^{2}$ In a continuous-time partial-equilibrium model without investment adjustment costs, the decision on the capital stock is static and so investment becomes in..nitely volatile. General-equilibrium models have introduced various forms of investment adjustment costs to improve the properties of the model, such as the persistence.

This note shows how investment adjustment costs interact with increasing returns in generating indeterminacy. The introduction of investment adjustment costs makes it diф cult for indeterminacy to occur. That is, the required degree of increasing returns is higher in the presence of investment adjustment costs. Plausible levels of investment adjustment costs mean that indeterminacy arises only if there is an implausible degree of returns to scale. Furthermore, models with large enough adjustment costs would never feature indeterminacy.

The relationship between indeterminacy and investment adjustment costs has also been analyzed by Guo and Lansing (1999), and Wen (in press), and Georges (1995) also gave examples of other adjustment costs and their infuence on indeterminacy. They show that adjustment costs would make it less likely that indeterminacy will occur. The unique contribution of this note is to present the relationship in a simple analytic way and to discuss the empirical plausibility of indeterminacy under adjustment costs.

This note proceeds as follows. Section 2 describes the model with investment adjustment costs. In section 3, we analyze the dynamics of the model and derive a necessary and suф cient condition for indeterminacy. Intuition is given for this condition, and its empirical plausibility is discussed. Section 4 concludes.

\section{The Economy}

This section introduces investment adjustment costs into the continuous-time model of B enhabib and Farmer (1994). Economic environment for ..rms and households is described, and their optimal behavior is derived.

\subsection{Firms}

In our model with increasing returns to scale, the aggregate production function is

$$
\mathrm{Y}=\mathrm{K}^{\circledR} \mathrm{L}^{-} ;{ }^{\circledR}>00^{-}>0 ;{ }^{\circledR}+^{-}, 1 ;
$$

\footnotetext{
${ }^{2} \mathrm{~K}$ im (1998) reviews the literature on investment adjustment costs from a macroeconomic perspective.
} 
where $\mathrm{Y} ; \mathrm{K}$, and $\mathrm{L}$ represent total output, the aggregate stock of capital, and aggregate labor hours, respectively. ${ }^{3}$ Unlike standard neoclassical growth models, we allow for increasing returns to scale. Benhabib and Farmer (1994) present two economic environments that are consistent with increasing returns. This note adopts the model with production externalities. ${ }^{4}$

Equation (1) is the social technology at the aggregate level and may be derived from the individual-level private technology of constant returns to scale:

$$
Y_{i}=X K_{i}^{a} L_{i}^{b} ; a>0 ; b>0 ; a+b=1 ;
$$

where the subscript $\mathrm{i}$ denotes the individual ..rm and the term $X$ represents production externalities exogenous to an individual ..rm. We assume that the externalities are such that

$$
X={ }^{3} K^{a} L^{b}{ }^{»} ; », 0:
$$

When $\gg=0$, the model reduces to the standard model with constant returns to scale at both the individual and the aggregate level. Suppose that factor markets are perfectly competitive, pro..t maximization conditions are

$$
\frac{Z K_{i}}{a}=\frac{W L_{i}}{b}=Y_{i}
$$

where $\mathbf{Z}$ is the rental rate of capital and $\mathrm{W}$ is the real wage.

Following the macroeconomic convention that the ..rms are symmetric and distributed over the real line [0; 1 , we substitute (3) into (2) and aggregate it over the ..rms to obtain the social production function (1) by de..ning

$$
\begin{aligned}
& \circledR=(1+\gg) a ; \\
& -=(1+\gg) b
\end{aligned}
$$

Likewise, the pro..t maximization conditions can also be written in terms of aggregate quantities,

$$
\begin{aligned}
& Z=\frac{a Y}{K} ; \\
& W=\frac{b Y}{L}:
\end{aligned}
$$

These two equations are interpreted as factor demand schedules. We assume that externalities are not strong enough to generate endogenous growth. That is, we restrict $\gg$ so that $\AA<1$.

\footnotetext{
${ }^{3}$ For notational simplicity, we suppress the time dependence of the variables.

${ }^{4}$ A nother environment is a monopolistically competitive economy. K im (1997) reviews three types of increasing returns in this type of models from a critical perspective.
} 


\subsection{Households}

The representative household maximizes

$$
Z_{1} \tilde{A} \log C ; \frac{L^{1+\hat{A}} !}{1+\hat{A}} e^{d^{1 / 2}} d t ; \hat{A}, 0 ; 1 / 2>0 ;
$$

where $\mathrm{C}$ is consumption. Parameters Â represents the inverse of the intertemporal elasticity of substitution for labor supply, and 1/2is the discount rate. The household budget constraint is

$$
\mathrm{C}+\mathrm{I}=\mathrm{ZK}+\mathrm{WL} \text {; }
$$

where I is the gross investment. The factor prices are taken as given.

The literature on investment adjustment costs has introduced the costs in various forms. In this note, we incorporate the presence of investment adjustment costs in the capital accumulation equation in a way similar to Lucas and Prescott (1971), ${ }^{5}$

$$
\mathrm{K}=\mathrm{K}{ }^{\underline{\mu}} \frac{\mu}{\mathrm{K}}^{\text {I }} ; \mathrm{K}(0) \text { given: }
$$

A variable with a dot above it represents its time derivative.

For later analysis of the local dynamics, we make three assumptions on the form of the adjustment costs function,

$$
\begin{gathered}
\underline{\mathrm{a}}(\sharp=0 ; \\
\underline{\mathrm{a}}^{0}(\sharp)=1 ; \\
\underline{\mathrm{a}}^{0}(\sharp)=0 ;
\end{gathered}
$$

The ..rst assumption de..nes the depreciation rate as the ratio between investment and capital at the steady state. The second assumption makes the steady state of our model with adjustment costs not dixerent from that of a model without adjustment costs. The standard linear capital accumulation, $\mathrm{K}=\mathrm{I} \mathrm{i} \mathbb{K}$, is an example without adjustment costs corresponding to ${ }^{a}{ }^{\infty}\left(\boxplus=0 .{ }^{6}\right.$ The degree of investment adjustment costs is represented by

$$
\tilde{A}=i \frac{\underline{\underline{\underline{a}}}^{\infty}(\boxplus)}{\underline{\underline{a}}^{0}(\boxplus)}
$$

\footnotetext{
${ }^{5}$ In the context of our model, the budget constraint (7) may incorporate investment adjustment costs in such a way that investment is less than savings as in A bel and Blanchard (1983) or that consumption plus savings is less than factor incomes. K im (1998) shows that these alternative speci..cations generate the dynamics equivalent to our speci..cation.

${ }^{6}$ In other words, we consider adjustment costs with only the second-order exects relative to the linear capital accumulation equation, without reference to the level or the ..rst-order exects. See K im (1998) for more on this point.
} 
In a model where .rms accumulate capital, this parameter is the inverse of the elasticity of $(I=K)$ with respect to Tobin's $q^{7}$

The optimizing behavior of the representative household is summarized in two equations. One is the labor supply equation,

$$
C L^{\hat{A}}=W ;
$$

and the other optimality condition relates consumption growth with the rental rate and investment adjustment costs as follows:

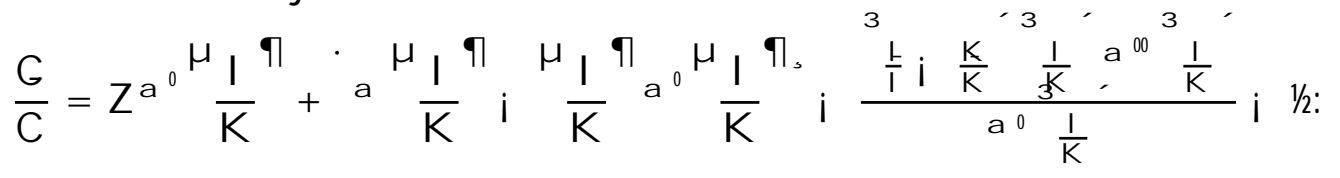

The right-hand side, excluding the discount rate term, would represent the interest rate of bonds if they were available to households.

\section{The Dynamics and Indeterminacy}

This section analyzes the dynamics of the model and derive a necessary and suф cient condition for indeterminacy. We give an intuition for this condition of indeterminacy and discuss the empirical plausibility of indeterminacy.

\subsection{The Dynamics}

The labor demand equation (5) and the labor supply equation (9) are combined into a labor market equilibrium condition,

$$
\frac{\mathrm{bY}}{\mathrm{L}}=\mathrm{CL} \hat{\mathrm{A}} \text { : }
$$

Replacing the rental rate in (10) with the demand for capital (4), we have an intertemporal optimality condition,

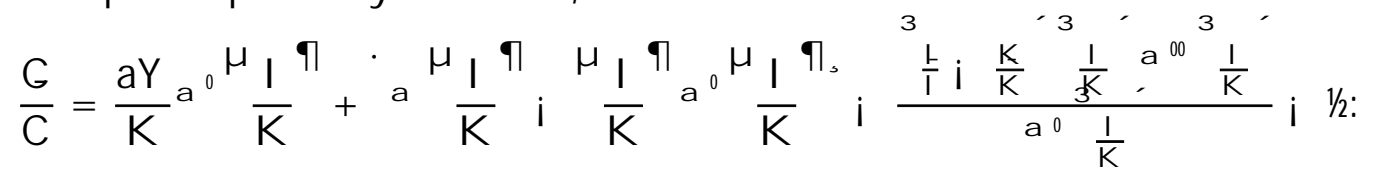

Using the two factor demand schedules, (4) and (5), we transform the budget constraint (7) into a resource constraint,

$$
\mathrm{C}+\mathrm{I}=\mathrm{Y} \text { : }
$$

\footnotetext{
${ }^{7}$ See the A ppendix A.1 for the derivation of this relation and the two optimality conditions in the next paragraph.
} 
Now the equilibrium is restricted by ..ve equations which consist of the aggregate production function (1), the capital accumulation equation (8), and (11)-(13).

A mong the ...ve variables in the system, labor $(L)$ is eliminated from the system by combining the aggregate production function (1) and the labor market equilibrium condition (11). Denoting lower-case letters for the logarithmic of the variables, we have

$$
\mathrm{y}=,+(1+\cdot) \mathrm{k}+{ }^{\circ} \mathrm{C} ;
$$

where

$$
\begin{aligned}
& =\frac{-\log b}{\hat{A}_{i}\left(^{-} \mathrm{i} 1\right)} \text {; } \\
& =\frac{\circledast(1+\hat{A})}{\hat{A}_{\mathrm{i}}(-\mathrm{i} 1)} \mathrm{i} 1 ; \\
& \circ=\frac{i^{-}}{\left.\hat{A}_{i}{ }^{-}{ }^{-} 1\right)} \text { : }
\end{aligned}
$$

We now have a four-variable system, but it is not easy to analyze its global dynamics. To discuss the local dynamics, we approximate this system by linearizing it with respect to the variables around their steady state. Once linearized, the system is reduced to the following bivariate ..rst-order system: ${ }^{8}$

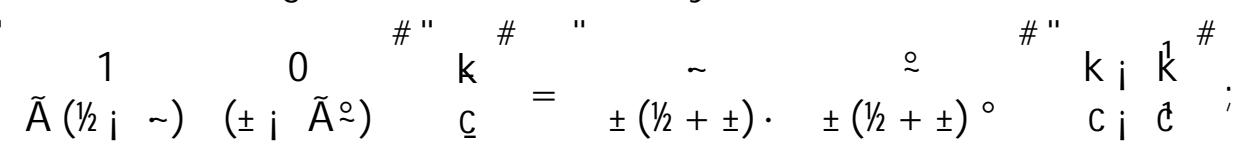

where

$$
\begin{aligned}
& \sim=\frac{1 / 2+ \pm}{a} \cdot \frac{1 / 2+b \pm}{a}=\frac{\left.1 / \hat{A}+ \pm t^{-} i 1\right)+(1 / 2+ \pm)}{\hat{A}_{i}\left(^{-} i 1\right)} ;
\end{aligned}
$$

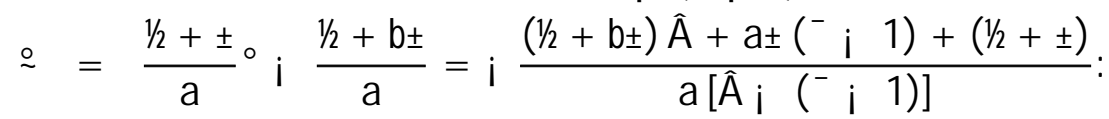

Variables with a bar represent their steady state.

\subsection{Condition for Indeterminacy}

In the standard growth model without externalities or increasing returns, there is a unique equilibrium path. Locally near the steady state, uniqueness implies that one of the two eigenvalues is negative and the other is positive. Indeterminacy in the growth model with variable labor and production externalities requires two

\footnotetext{
${ }^{8}$ See the A ppendix A.2 for detailed derivation of this bivariate system.
} 
negative eigenvalues. Since the trace and the determinant of the J acobian are the sum and the product of the eigenvalues, the necessary and sul cient condition for indeterminacy is that the trace is negative and that the determinant is positive.

The J acobian of our ..rst-order system is

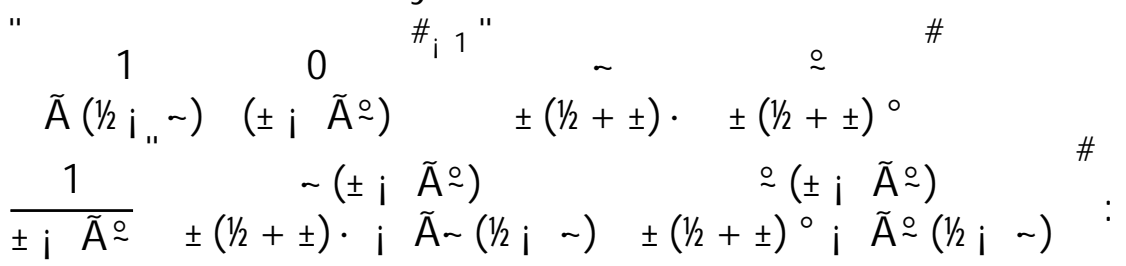

Its trace and determinant are expressed in terms of original parameters as follows:

$$
\begin{aligned}
& \operatorname{Tr}=\frac{a \pm(1 / 2+ \pm(1+\hat{A}) »}{\left.a \pm\left[\hat{A} i \quad{ }^{-} i \quad 1\right)\right]+\hat{A}\left[\left(1 / 2+b \pm \hat{A}+a \pm\left(^{-} ; \quad 1\right)+(1 / 2+ \pm]\right.\right.}+1 / 2 \\
& \text { Det }=i \frac{ \pm(1+\hat{A})(1 ; \quad B)(1 / 2+ \pm(1 / 2+b \pm)}{\left.a \pm\left[\hat{A} i \quad{ }^{-} i \quad 1\right)\right]+\hat{A}\left[\left(1 / 2+b \pm \hat{A}+a \pm\left(^{-} i \quad 1\right)+(1 / 2+ \pm]\right.\right.} \text { : }
\end{aligned}
$$

Now we are ready to calculate the necessary and suф cient condition of indeterminacy in our model with investment adjustment costs. Indeterminacy arises if and only if the parameter values satisfy the following two conditions:

$$
\tilde{A}<1 ;
$$

and

$$
\text { - } i 1>\hat{A}+(1+\hat{A}) \frac{\tilde{A} \frac{1 / 2+ \pm}{a \pm}}{\frac{\tilde{A}}{1_{i} \tilde{A}}} !
$$

Since the determinant passes through minus in..nity to plus in..nity, the condition involving the trace is not binding.

The ..rst condition says that the degree of adjustment costs should be less than unity. In terms of q-regressions, the elasticity of $(I=K)$ with respect to q should be larger than unity. This condition puts an upper bound on the degree of adjustment costs for indeterminacy to arise. If the degree of adjustment costs is as big as unity, indeterminacy will never occur regardless of the degree of externalities. The case of unitary degree of adjustment costs in our continuous-time model corresponds to the loglinear capital accumulation equation in a discrete-time model, as in Hercowitz and Sampson (1991). Guo and Lansing (1999) show that indeterminacy does not arise under this loglinear capital accumulation equation.

Using the relation that ${ }^{-}=(1+\gg) b$, we rewrite the second condition in terms of the degree of externalities,

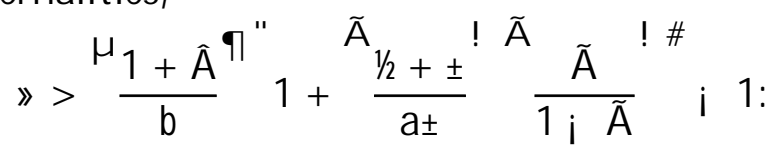


For convenience of the discussion, we de. .ne the right hand side as the required degree of externalities for indeterminacy to occur. The required degree of externalities is an increasing function of the degree of adjustment costs $(\tilde{A}) .^{9}$ Furthermore, the required degree increases very fast since it is a rational function with respect to the degree of adjustment costs. As the degree of adjustment costs approaches unity, the required degree of externalities diverges to in...nity.

\subsection{Intuition for Indeterminacy}

In this subsection, we give an intuition for the condition of indeterminacy in a model with investment adjustment costs. The best way to approach our intuition is to start from the condition of indeterminacy in a model without adjustment costs and its intuition. If there are no adjustment costs (i.e. $\tilde{A}=0$,) the ..rst condition (14) is automatically satis..ed and the second condition (15) is simpli..ed as follows:

$$
\text { - i } 1>\hat{A} \text {; }
$$

as derived in Benhabib and Farmer (1994).

An economic meaning of this condition becomes very intuitive if we rewrite the labor market equilibrium condition (11) as follows:

$$
b K^{\circledR} L^{-} i^{1}=W=C L^{\hat{A}}:
$$

Now the intuition of indeterminacy is straightforward. The condition (17) means that the labor demand schedule slopes up as a function of the real wage and is steeper than the labor supply curve. This intuition from the labor market equilibrium has been used widely in the literature on indeterminacy. ${ }^{10}$

However, it is easy see that there are pitfalls in this interpretation. This note shows that, in a model with investment adjustment costs, the labor market equilibrium condition (18) remains unchanged but that the condition for indeterminacy is

\footnotetext{
${ }^{9} \mathrm{Guo}$ and Lansing (1999) and Wen (in press) also show the positive relationship between the required degree of externalities and the degree of investment adjustment costs. However, this relationship is not analytically derived as in (15). For example, Wen (in press) does not comment on the upper bound, such as (14), on the degree of adjustment costs for indeterminacy to arise. Furthermore, his conclusion that the oscillation mechanism is preserved even under a unique equilibrium depends on the speci..cation that adjustment costs are a function of the ..rst dixerence in investment. In our model where the level of investment determines the costs, the oscillation mechanism disappears together with indeterminacy.

${ }^{10}$ See B enhabib and Farmer (1994) and some references in B enhabib and Farmer (1997). A ccording to this intution, increasing returns justify households' optimism of market returns on labor, which would then induce both higher employment and a higher wage rate.
} 
dixerent from (17). That is, the intuition from the labor market does not hold in our model with investment adjustment costs.

In contrast, this note gives an intuition for indeterminacy from the market for capital. Indeterminacy arises because shifts in investor beliefs about future investment returns are self-reinforcing: if investment increases in response to high prospective returns, the resulting capital formation brings about the necessary high returns. However, investment adjustment costs weaken this linkage and requires higher degree of increasing returns for indeterminacy to arise.

Intuitively speaking, less ‡exibility in investment returns due to adjustment costs should be oxset by more łexibility in increasing returns for optimism to be selfful..lling. This intuition is similar to the one given by Guo and Lansing (1998) in a model of stabilization policy. Government's stabilization policy, in a form of progressive taxation, taxes away the high returns from belief-driven investment. As a result, it is diф cult for indeterminacy to arise.

\subsection{Plausibility of Indeterminacy}

To provide an idea on the plausibility of indeterminacy, we analyze the sensitivity of the required degree of externalities with respect to the degree of adjustment costs. For concreteness of this analysis, we calibrate all the parameters besides the degree of adjustment costs $(\tilde{A})$ and the degree of externalities (»). We follow the benchmark values of Benhabib and Farmer (1996) except for $\hat{A}$,

\begin{tabular}{|c|c|c|c|c|c|}
\hline Parameter & $\mathrm{a}$ & $\mathrm{b}$ & $\mathrm{A}$ & $1 / 2$ & \pm \\
\hline Calibrated value & 0.3 & 0.7 & 0 & 0.05 & 0.1 \\
\hline
\end{tabular}

Our calibration of $\hat{A}$ makes it favorable for indeterminacy to arise, since $\hat{A}=0$ minimizes the required degree of externalities represented by the right-hand side of (16). ${ }^{11}$

Now we analyze the space of $\tilde{A}$ and $\gg$ for indeterminacy to occur. As reviewed in Hamermesh and P fann (1996), the estimates of the degree of investment adjustment costs are few and vary widely. The lower bound of empirical estimates for $\tilde{A}$ is about 0.2. Here we consider the range of $\tilde{A}$ between 0 and 0.2 , to be conservative in concluding that investment adjustment costs makes it implausible for indeterminacy to arise.

\footnotetext{
${ }^{11}$ The benchmark value of $\hat{A}$ is 1 in B enhabib and Farmer (1996).
} 
W ith the calibrated parameter values in the previous table, the mapping from the degree of adjustment costs to the required degree of externalities is as follows:

\begin{tabular}{|c|c|c|c|c|c|}
\hline the degree of adjustment costs (A) & 0 & $0: 05$ & $0: 1$ & $0: 15$ & $0: 2$ \\
\hline the required degree of externalities & 0.4286 & 0.8043 & 1.2222 & 1.6891 & 2.2143 \\
\hline
\end{tabular}

It is easy to see that the required degree of externalities increases faster as the degree of adjustment costs increases. Furthermore, since the required degree of externalities increases so fast that indeterminacy does not arise under plausible degree of externalities. Even when the degree of adjustment costs is very low at $0: 05$, the required degree of externalities is too large at 0:8043 which implies the returns to scale of 1:8043.

\section{Conclusion}

We have shown how the presence of positive investment adjustment costs makes it less likely that indeterminacy will occur. The larger the adjustment costs, the larger the required degree of increasing returns. Under empirically plausible parameter values for investment adjustment costs, we need implausibly large degree of increasing returns to generate indeterminacy.

\section{A ppendix}

\section{A.1. Behavior of Households}

The representative household maximizes (6) subject to (7) and (8). The currentvalue Hamiltonian is

$$
H=\log C ; \frac{L^{1+\hat{A}}}{1+\hat{A}}+{ }^{\prime}(Z K+W L ; C ; \quad)+! K a^{a} \frac{\mu}{K}^{q} ;
$$

where ' and ! are the marginal utility of an extra income and capital, respectively. The ..rst-order conditions for $C ; L ; I$; and $K$ are

$$
\begin{aligned}
& \begin{array}{l}
\frac{1}{C}=' ; \\
L^{\AA}=' W ;
\end{array} \\
& =! a^{0}{ }^{\mu} \overline{\mathrm{I}}^{\mathrm{q}}{ }^{\mathrm{N}} \text {; }
\end{aligned}
$$

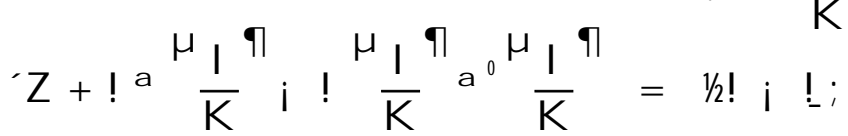


Combining the conditions for consumption and labor, we have the labor supply equation:

$$
C L^{\hat{A}}=W:
$$

Note that the parameter Â represent the elasticity of labor supply conditional on consumption. In our setup where capital is accumulated by households rather than by ..rms, Tobin's q (the marginal value of capital measured in output) would be

$$
q=\frac{!}{-}:
$$

This transforms the condition for investment into

$$
q=\frac{\frac{1}{3}}{a 0} \frac{1}{K} ;
$$

whose linearization produces a q-regression in logs,

$$
\log ^{\mu} \frac{1}{K}^{q}=\log \pm+\frac{1}{\tilde{A}} \log q:
$$

The properties of q rewrite the condition for capital as follows:

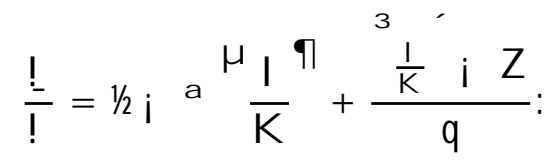

These properties, again, transforms this equation into the dynamic optimality condition for households (10),

$$
\frac{C}{C}=R ; 1 / 2
$$

where

$$
\begin{aligned}
& R=\frac{Z+q^{a^{3}} \frac{1}{k} i^{3} \frac{1}{K}^{\prime i}+q}{q}
\end{aligned}
$$

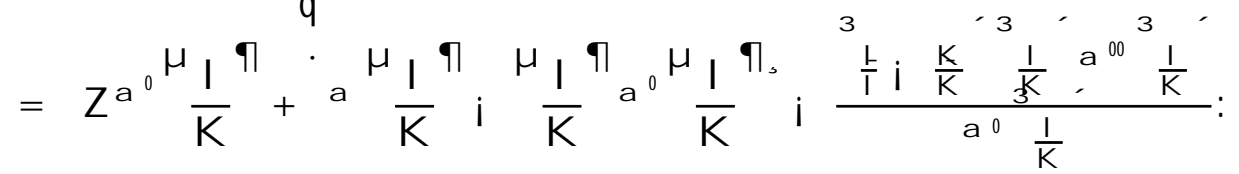

The variable $\mathrm{R}$ would represent the interest rate of bonds if they were available to households. 


\section{A.2. A nalysis of the Dynamics}

Five equations governing the dynamics are the aggregate production function (1), the capital accumulation equation (8), the labor market equilibrium condition (11), the intertemporal optimality condition (12), and the resource constraint (13). As done in the text, we eliminate labor ( $L$ ) from the system by combining the aggregate production function (1) and the labor market equilibrium condition (11),

$$
\mathrm{y}=,+(1+\cdot) \mathrm{k}+{ }^{\circ} \mathrm{C} \text {; }
$$

where

$$
\begin{aligned}
& =\frac{-\log b}{\hat{A}_{i}\left({ }^{-} i 1\right)} \text {; }
\end{aligned}
$$

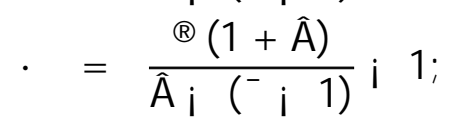

$$
\begin{aligned}
& \circ=\frac{\mathrm{i}^{-}}{\hat{\mathrm{A}}_{\mathrm{i}}\left(^{-} \mathrm{i} 1\right)} \text { : }
\end{aligned}
$$

Now we derive the bivariate ..rst-order system in detail.

First, we linearize the function representing investment adjustment costs around the argument's steady state $\left(I^{2}=\mathbb{R}^{2}= \pm,_{1}^{12}\right.$

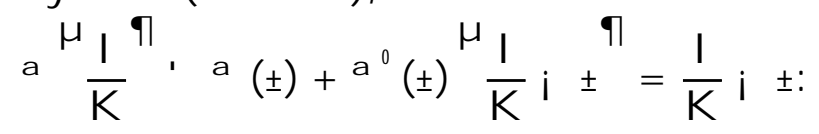

This approximation transforms the capital accumulation equation (8) as follows:

$$
\frac{\mathrm{K}}{\mathrm{K}}=\underline{\mathrm{a}}^{\mu} \frac{\mathrm{I}}{\mathrm{K}}^{\text {ๆ }}, \frac{\mathrm{I}}{\mathrm{K}} \mathrm{i} \pm
$$

which is equivalent to the capital accumulation equation without adjustment costs, $\mathrm{K}=\mathrm{I} \mathrm{i} \mathbb{K}$. That is, adjustment costs are not introduced in the ..rst order.

Second, linearization of the intertemporal optimality condition (12) needs the following approximations,

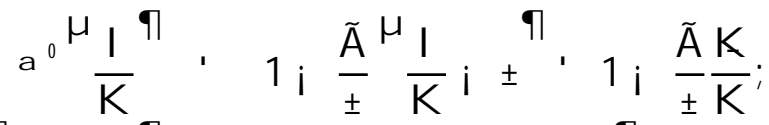

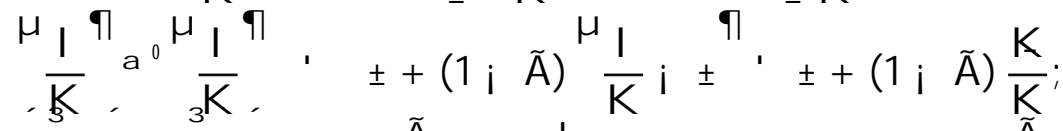

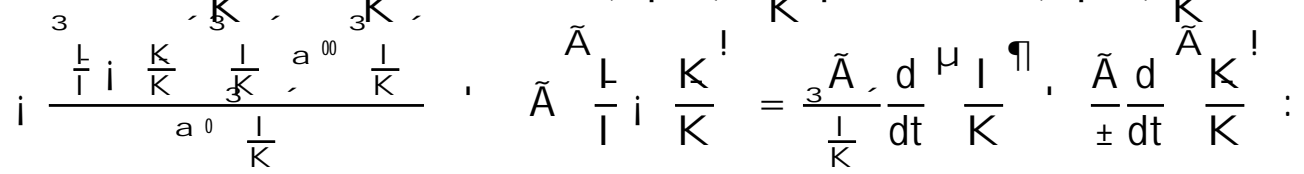

\footnotetext{
${ }^{12}$ We use the notation, ' , when we approximate a function with respect to variables around the steady state.
} 
Now we linearize the intertemporal optimality condition (12) as follows:

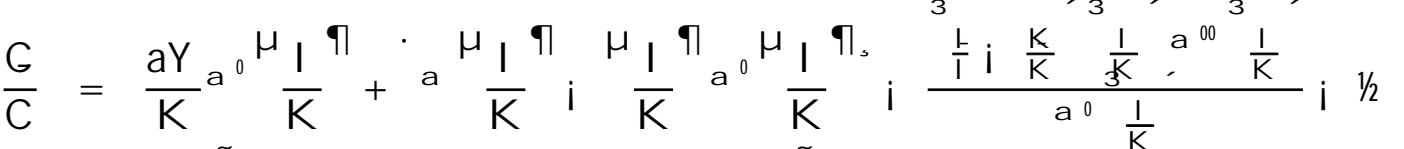

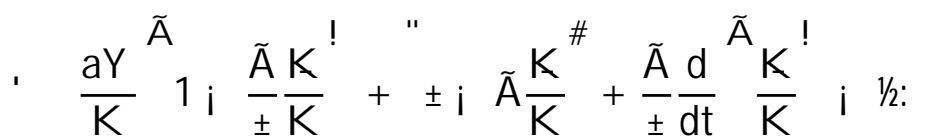

Third, we express the two linearized dynamic equations in terms of only capital $(\mathrm{K})$ and consumption (C). The resource constraint (13) is used in transforming the linearized capital accumulation equation,

$$
\mathrm{k}=\frac{\mathrm{K}}{\mathrm{K}}, \frac{\mathrm{l}}{\mathrm{K}} \mathrm{i} \pm=\frac{\mathrm{Y} \mathrm{i} C}{\mathrm{~K}} \mathrm{i} \pm=\frac{\mathrm{Y}}{\mathrm{K}} \mathrm{i} \frac{\mathrm{C}}{\mathrm{K}} \mathrm{i} \pm=\mathrm{e}^{+\cdot \mathrm{k}+{ }^{\circ} \mathrm{C}} \mathrm{i} \mathrm{e}^{\mathrm{i} k+\mathrm{c}} \mathrm{i} \pm
$$

and we rewrite the linearized intertemporal optimality condition as follows:

$$
\underline{c}=\frac{C}{C}, \quad a e^{+\cdot k+{ }^{\circ} C^{\tilde{A}}} 1_{i} \frac{\tilde{A}}{ \pm} k^{!} i^{3} \pm_{i} \tilde{A} k+\frac{\tilde{A}}{ \pm} k_{i}{ }^{1 / 2}
$$

Fourth, linearizing this autonomous system of $k$ and $c$, we will get the bivariate ..rst-order linear system. Linearization requires calculating the steady state, and the relevant information on the steady state is

$$
\begin{aligned}
& e^{+\cdot k+{ }^{\circ} z}=\frac{\vec{Y}}{\vec{K}}=\frac{1 / 2+ \pm}{a} ; \\
& e^{i k+z}=\frac{c}{k^{k}}=\frac{1 / 2+b \pm}{a}:
\end{aligned}
$$

Now linearizing the linearized capital accumulation equation, we have

$$
\begin{aligned}
& k^{\prime} e^{+\cdot k+{ }^{\circ} c} \dot{A} e^{i k+c} i \pm
\end{aligned}
$$

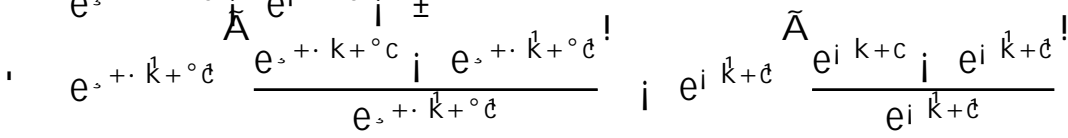

$$
\begin{aligned}
& \text { 1 } \frac{1 / 2+ \pm^{h}}{3 a} \cdot k_{i} k^{\prime}+{ }^{\circ}\left(c_{i} \quad E\right)^{i} i \frac{1 / 2+b \pm^{h}}{a} i^{3} k_{i} k^{\prime}+\left(c_{i} \quad E\right) \\
& =\sim k_{i} k+\stackrel{2}{*}\left(\begin{array}{cl}
E & E
\end{array}\right) \text {; }
\end{aligned}
$$

where

$$
\begin{aligned}
& \sim=\frac{1 / 2+ \pm}{a}+\frac{1 / 2+b \pm}{a}=\frac{\left.1 / \hat{A}+ \pm^{-} i 1\right)+(1 / 2+ \pm)}{\hat{A}_{i}\left({ }^{-} i 1\right)} ;
\end{aligned}
$$

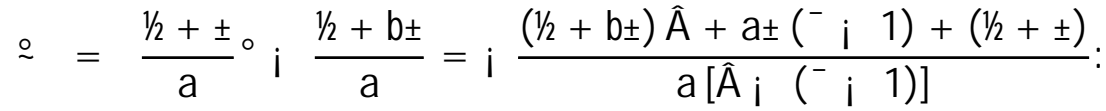


Replacing $k$ of the linearized intertemporal optimality condition with the derivative of the above equation and then linearizing it, we have

$$
\begin{aligned}
& \underline{c}^{\prime} a e^{+\cdot k+{ }^{\circ} \mathrm{A}} 1_{i} \frac{\tilde{A}}{ \pm} k^{!} i^{3} \pm_{i} \tilde{A} k+\frac{\tilde{A}}{ \pm} k_{i}{ }^{1 / 2}
\end{aligned}
$$

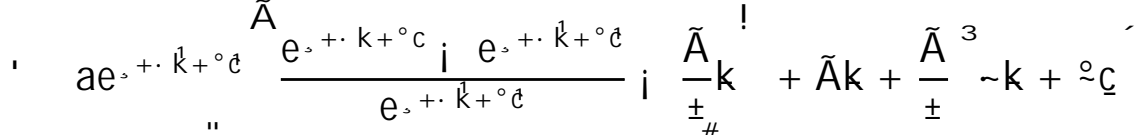

$$
\begin{aligned}
& \text { ' }(1 / 2+ \pm)^{3} k_{i} \dot{k}^{\prime}+{ }^{\circ}\left(c_{i} \quad \varepsilon\right) i \frac{\tilde{A}}{ \pm} k^{\#}+\tilde{A} k+\frac{\tilde{A}^{3}}{ \pm}-k+{ }^{\circ} \underline{C}
\end{aligned}
$$

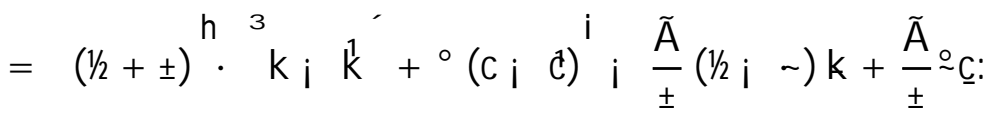

Multiplying \pm on both sides, we rewrite this equation as

$$
\tilde{A}(1 / 2-7) k+\left( \pm_{i} \tilde{A}^{0}\right) \underline{c}^{\prime} \pm\left(1 / 2+\#^{h} \cdot{ }^{3} k_{i} \hat{k}^{\prime}+{ }^{\circ}\left(c_{i} \quad\right)^{i}:\right.
$$

This completes the derivation.

\section{R eferences}

[1] A bel, A ndrew B. and Olivier J . Blanchard (1983), "A n Intertemporal M odel of Saving and Investment," Econom etrica, 51(3), 675-692.

[2] B enhabib, J ess and Roger E. A. Farmer (1997), "Indeterminacy and Sunspots in Macroeconomics," forthcoming in $\mathrm{H}$ andbook of $\mathrm{M}$ acroeconom ics edited by J ohn Taylor and Michael Woodford.

[3] Benhabib, J ess and Roger E. A. Farmer (1996), "Indeterminacy and SectorSpeci..c Externalities," Joumal of M onetary E conom ics, 37, 421-443.

[4] Benhabib, J ess and Roger E. A. Farmer (1994), "Indeterminacy and Increasing Returns," Joumal of $\mathrm{E}$ conom ic $\mathrm{T}$ heory, 63, 19-41.

[5] Georges, Christopher (1995), "Adjustment Costs and Indeterminacy in Perfect Foresight Models," Joumal of Econom ic D ynam ics and Control, 19, 39-50.

[6] Guo, J ang-Ting, and Kevin J . Lansing (1999), "Fiscal Policy, Increasing Returns, and Endogenous Fluctuations," mimeo.

[7] Guo, J ang-T ing, and K evin J . Lansing (1998), "Indeterminacy and Stabilization Policy," Joumal of E conom ic Theory, 82, 481-490. 
[8] Hamermesh, Daniel S. and Gerard A. Pfann (1996), "Adjustment Costs in Factor Demand," Joumal of Econom ic Literature, 34, 1264-1292.

[9] Hercowitz, Zvi, and M ichael Sampson (1991), "O utput Growth, the Real Wage, and Employment Fluctuations," Am erican E conom ic Review , 81, 1215-1237.

[10] K im, J inill (1998), "Speci..cations of Investment Adjustment Costs in a Simple Dynamic Model," Finance and Economics Discussion Series 1998-39, Federal Reserve B oard.

[11] K im, J inill (1997), "Three Sources of Increasing R eturns to Scale," Finance and E conomics Discussion Series 1997-18, Federal Reserve B oard.

[12] Lucas, Robert E. J r., and Edward C. Prescott (1971), "Investment under Uncertainty," Econom etrica, 39, 659-681.

[13] Wen, Y i (in press), "Indeterminacy, Dynamic Adjustment Costs, and Cycles," Econom ics Letters. 